Chapter 9

\title{
PET-CT in Anal Cancer: Indications and Limits
}

\author{
Massimiliano Mistrangelo and Adriana Lesca \\ Additional information is available at the end of the chapter \\ http://dx.doi.org/10.5772/57121
}

\section{Introduction}

Perianal and anal canal malignancies are uncommon. The anal canal is a small area, rather complex for the presence of different histological features and for the lymphatic spread [1].

In the IUCC, American Joint Committee on Cancer (AJCC) and World Health Organization (WHO) staging systems the anal canal is described as the last part of the gastrointestinal tract extending from the anal ring at the level of the puborectalis muscle (where the rectum enters the pelvic floor), to the perianal tissue that is the junction of the hair- bearing skin and the nonkeratinizing squamous epithelium of the distal anal canal.

As cited tumors of the anal canal can present different histological features. These guidelines refer to squamous cell carcinoma (including the so called cloacogenic variant) which constitutes $80 \%$ of all lesions of this area and derives from transitional and squamous cell epithelium. In some pathology literature squamous cell carcinoma of the anal canal is also described according to additional histopathologic feature such as keratinization, presence of mucin and abundance of basement mebrane-like material.

Less common are adenocarcinoma and mucinous adenocarcinoma of the anal glands or of fistula tracts that must be distinguished from very low rectal cancers. Other uncommon neoplasms of the anal canal include small cell carcinoma, carcinoid and other neuroendocrine tumors, malignant melanoma, squamous cell papilloma, papillary hidradenoma, keratoacanthoma, mesenchymal and neurogenic tumors, lymphoma, leiomyosarcoma, and secondary tumors.

Tumors originating from the anal margin should be staged as skin cancer: they can be squamous cell cancer, basal cell cancer, Bowen's or Paget's disease.

This is an important distinction as skin cancers rarely involve lymph nodes or lead to distant metastases [2-4]. 


\section{Incidence}

Anal cancer remains a rare disease but its incidence is increasing [5], mainly in association with human papillomaviruses (HPV) infection. An estimated 5820 new cases (2140 men and 3680 women) were estimated to occur in the United States in 2011, accounting for approximately $2.1 \%$ of digestive system cancers. It has been estimated that 770 deaths due to anal cancer will occurr in U.S. alone in 2011 [6].

In western Europe the average annual incidence of anal carcinoma is 1 to 3 cases per 100,000 with a female prevalence (two to four times that of men [7]) and a highest incidence during the sixth and seventh decades of life [8]. The annual incidence incidence can be up to 35 per 100,000 in men who practice anal-receptive sexual intercourse, and those who are human immunodeficiency virus (HIV)-positive have twice the risk of those who are not [7].

In particular, squamous cell carcinoma (the other names, epidermoid or spinocellular, are no longer used) is the most common histological type of anal carcinoma and constitutes up to the $80 \%$ of all malignant anal tumours [9].

\section{Etiology}

Chromosome 11 deletions (11q22) or the short arm of chromosome 3 (3p22), environmental factors such as cigarette smoking, sexual orientation and a high number of sexual partners, anoreceptive intercourse, male homosexuality, viral infections of the anogenital area (human papillomavirus (HPV) virus type 16 and 18) and immunodeficiency, are all considered as causative factors of anal cancer [8, 10-11].

The introduction of antiretroviral drugs have improved the life expectancy of HIV- positive patients. This has contributed to increasing the incidence of anal cancer in this population.

HPV infection (type 16 in about $87 \%$ of cases [12]) and anogenital warts are closely associated with anal cancer. Anal canal lesions are more often HPV positive than perianal lesions. Ninetyfive percent of anal canal cancer in women and $83 \%$ in men is HPV- positive while cancer located at the anal margin are HPV- positive in only $80 \%$ of women and $28 \%$ of men [12]. Because of this high association with anal cancer HPV is considered to be the most important causative factor much like in cases of cervical cancer [13-16].

In particular, HPV is involved in the pathogenesis of anal intraepithelial neoplasia (AIN) which progresses from dysplasia to invasive cancer. HPV type 16 seems to be associated with a higher risk of malignant transformation [17].

Other viral infections such as herpes simplex virus (HSV) have been studied but are considered to play only a marginal role in disease progression. 
After solid organ transplant, patients receive chronic immunosuppressive therapy, so they are exposed to higher risk of various squamous cell carcinoma, such as of the anal canal [11]. Moreover, the use of corticosteroids can increase the risk of developing anal cancer [18].

Several studies made a connection between cigarette smoking and risk of developing anal cancer, and this risk diminished after smoking cessation [19].

\section{Clinical manifestations}

Macroscopically the squamous anal cancer appears as a small ulceration or fissure, exophytic, with indurated margins and irregular thickening [20]. Sometimes large lesions are observed.

Symptoms are rectal bleeding, rectal pain, tenesmus or mass sensation, but about $20 \%$ of patients are asymptomatic at the time of diagnosis [6].

\section{Treatment}

Prior to the mid-1980s, the treatment of choice for anal cancer was abdominoperineal resection (APR). The 5-year survival rate after APR for anal cancer was 40-70\%, with worse outcomes for those with larger tumors and nodal metastases. In the 1920s and 1930s inguinal node dissection was included in the surgical management of these patients, and it was generally reserved for those patients with clinically enlarged (though not necessarily involved) inguinal nodes [21]. By the 1950s it had became clear that the morbidity associated with lymph node dissection was much greater than any survival benefit, so the procedure was gradually abandoned [22]. In 1974 Nigro proposed a multimodality treatment combining radiation and chemotherapy which has since then become the standard treatment with surgery reserved for salvage treatment following local failure [23]. Local control rates of $60-90 \%$ over all stages are achievable, with sphincter preservation in about $65 \%$ of cases. The prognosis after combined radiochemotherapy for anal cancer may be influenced by several factors: high tumor stage and regional nodal involvement; tumor site in the anal canal; inguinal lymph node involvement in anal canal carcinoma. Synchronous inguinal metastases occur in $10-25 \%$ of patients [24] and constitute an independent prognostic factor for local failure and overall mortality according to a multivariate analysis in a phase 3 EORTC trial [25]. Metachronous metastases have been reported in $5-25 \%$ of patients [10].

Adverse effects of chemoradiation therapy can be mucositis, diarrhea, skin desquamation and erytema, mielosuppression, ulcers, fistulae, necrosis, and stenosis [19]. Surgery treatment is reserved for salvage theraphy, in subjects with persistent or recurrent disease [19, 26-28]. The elective treatment of metastatic disease (often hepatic nodules), is chemotherapy; therapeutic plans include cisplatin and 5-FU, carboplatin, doxorubicin and semustine [29-32]. 


\section{Diagnosis}

Clinical workup in the staging of anal cancer comprises digital rectal examination, anoscopy with biopsy of suspicious lesions, palpation of inguinal lymph nodes, tumor marker assay, chest X-ray, rigid proctoscopy, total colonoscopy, rectal endosonography, contrast-enhanced diagnostic computed tomography (CT) and/or magnetic resonance imaging (MRI).

In effect, physical examination, biopsy of the tumor and endorectal ultrasonography can help in determining the tumor depth and the invasion of perirectal limph nodes; instead, palpation of the groin, CT and MRI can give important information about inguinal and iliac lymph node involvement and the evidence of distant visceral metastasis. In recent years, fluorodeoxyglucose-positron emission tomography (18F-FDG-PET/CT) has rapidly gained a expanding role in oncology, with mounting evidence for its effectiveness in the staging and management of various types of tumors.

\section{PET-CT and tumor}

2-deoxy-2[F-18]fluoro-D-glucose (FDG) Positron Emission Tomography (PET) scan is a medical examination currently approved and used in the staging work-up of primary cancers of several sites, such as lung, head and neck, oesophagus, breast, colorectum, melanoma, the Hodgkin's disease and non-Hodgkin's limphomas.

High rates of glycolysis are found in many malignant tumor cells and high uptake of FDG is usually associated with a high expression of glucose transporters. Many tumors are avid of FDG and PET/CT scan can help in staging the primary cancer, in choosing the best side for biopsy, in evaluating the treatment response, in searching other synchronous tumors, in suspect recurrence of tumor with markers increasing, and in planning radiation treatment. We must remember that increased FDG uptake is not specific for neoplasm but inflammatory processes may also show increased uptake, so that abscesses, tuberculosis, inflammations, fungal infections, inflammation related to radiation treatment can concentrate radioglucose, causing false positive results [33].

Evaluation of PET images can be performed visually or semiquantitatively, using the Standardized Uptake Value (SUV). Semiquantitative evaluation offers a more objective way of reporting lesion than visual image interpretation and is useful for comparing lesion activity in consecutive studies. However, visual interpretation is equally effective for one-time diagnosis [33].

\section{PET-CT and anal cancer}

Since 2005, the use of PET-CT in anal cancer has been described [34-54]. As suggested by Grigsby et al., the advantage of FDG-PET/CT is that it can address all three staging criteria of 
the TNM system in a single whole-body imaging procedure: demonstrate the extent of the primary tumor; detect lymph node metastases; and reveal any sites of distant metastases [55]. The 2007 National Comprehensive Cancer Network treatment guidelines included PET/CT as a part of the standard pre-treatment workup of patients diagnosed with anal carcinoma [56]. The new version 2.2012 consider PET-CT scan for work up, even if its use for staging or treatment planning has not been validated [57]. The Authors suggest that PET-CT actually does not replace a diagnostic CT scan [57].

\section{Detection of primary neoplam}

Evidence from published data indicates that PET/CT is clearly superior to CT in visualizing the biopsy-proven primary tumor, although the lack of sensitivity did not affect treatment. Analyzing the Literature PET-CT detected the primary anal tumor in 59-100\% of cases, while CT scan only in $47-75 \%$. In almost all large series are included some patients, who previously were submitted to surgical removal of the anal cancer but with histologically confirmed positive surgical margins. In these cases PET-CT resulted negative (false negative). When we exclude these patients by the review, the percentage of the detection of the primary neoplasm with PET-CT arises to $87.5-100 \%$ of cases. This suggests that both PET/CT and CT were unable to detect residual tumor after surgical excision.

Results are repoted in Table 1 [34-54]. Figures 1 and 2 present two cases of PET-CT positive for anal cancer.

\begin{tabular}{cccccc}
\hline Author, year & $\begin{array}{c}\text { Patients } \\
\text { (Total) }\end{array}$ & Detection & $\begin{array}{c}\text { Previous } \\
\text { surgery }\end{array}$ & $\begin{array}{c}\text { Excluding previous } \\
\text { surgery }\end{array}$ & $\begin{array}{c}\text { Detection CT } \\
\text { scan }\end{array}$ \\
\hline Trautmann, 2005 & 21 & $21 / 21(100 \%)$ & 0 & $21 / 21(100 \%)$ & n.r. \\
\hline Cotter, 2006 & 41 & $31 / 41(75.6 \%)$ & 7 & $31 / 34(91 \%)$ & $20 / 34(59 \%)$ \\
\hline Piperkova, 2006 & 1 & $1 / 1(100 \%)$ & 0 & $1 / 1(100 \%)$ & $1 / 1(100 \%)$ \\
\hline Anderson, 2007 & 3 & $3 / 3(100 \%)$ & 0 & $3 / 3(100 \%)$ & n.r. \\
\hline Joon, 2007* & 48 & $40 / 48(83.3 \%)$ & 7 & $40 / 41(97.5 \%)$ & $24 / 41(58.5 \%)$ \\
\hline Schwarz, 2008 & 53 & n.r. & n.r. & n.r. & n.r. \\
\hline Nguyen, 2008* & 48 & $40 / 48(83.3 \%)$ & 7 & $40 / 41(97.5 \%)$ & $22 / 38(58 \%)$ \\
\hline lagaru, 2009 & 8 & $7 / 8(87.5 \%)$ & 0 & $7 / 8(87.5 \%)$ & n.r. \\
\hline de Winton, 2009 & 61 & $45 / 61(73.7 \%)$ & 16 & $45 / 45(100 \%)$ & n.r. \\
\hline Forrest, 2009 & 39 & $38 / 39(97 \%)$ & 0 & $38 / 39(97 \%)$ & $22 / 39(56 \%)$ \\
\hline Renaud, 2009 & 20 & $20 / 20(100 \%)$ & n.r. & $20 / 20(100 \%)$ & n.r. \\
\hline Kidd, 2010 & 77 & n.r. & n.r. & n.r. & n.r. \\
\hline Krengli, 2010 & 27 & $26 / 27(96.3 \%)$ & n.r. & $26 / 27$ & n.r. \\
\hline Bannas, 2010 & 22 & $15 / 17(88 \%)$ & n.r. & $15 / 17(88 \%)$ & $8 / 22(47 \%)$ \\
\hline Engledow, 2010 & 40 & $40 / 40(100 \%)$ & n.r. & $40 / 40(100 \%)$ & n.r. \\
\hline
\end{tabular}




\begin{tabular}{cccccc}
\hline Author, year & $\begin{array}{c}\text { Patients } \\
\text { (Total) }\end{array}$ & Detection & $\begin{array}{c}\text { Previous } \\
\text { surgery }\end{array}$ & $\begin{array}{c}\text { Excluding previous } \\
\text { surgery }\end{array}$ & $\begin{array}{c}\text { Detection CT } \\
\text { scan }\end{array}$ \\
\hline Vercellino, 2011 & 22 & $13 / 22(59 \%)$ & 8 & $13 / 14(92.8 \%)$ & n.r. \\
\hline Sveistrup, 2012 & 91 & $89 / 91(97 \%)$ & 4 & $87 / 87(100 \%)$ & n.r. \\
\hline Mistrangelo, 2012 & 53 & $47 / 53(88.7 \%)$ & 5 & $47 / 48(97.9 \%)$ & $30 / 40(75 \%)$ \\
\hline Wells, 2012 & 30 & $28 / 30(93 \%)$ & 2 & $28 / 28(100 \%)$ & n.r. \\
\hline Bhuva, 2012 & 43 & $40 / 43(93 \%)$ & n.r. & n.r. & n.r. \\
\hline
\end{tabular}

PS: * The 2 papers were published separately considering the same series.

n.r.: Not Reported

Table 1. Detection of primary neoplasm.

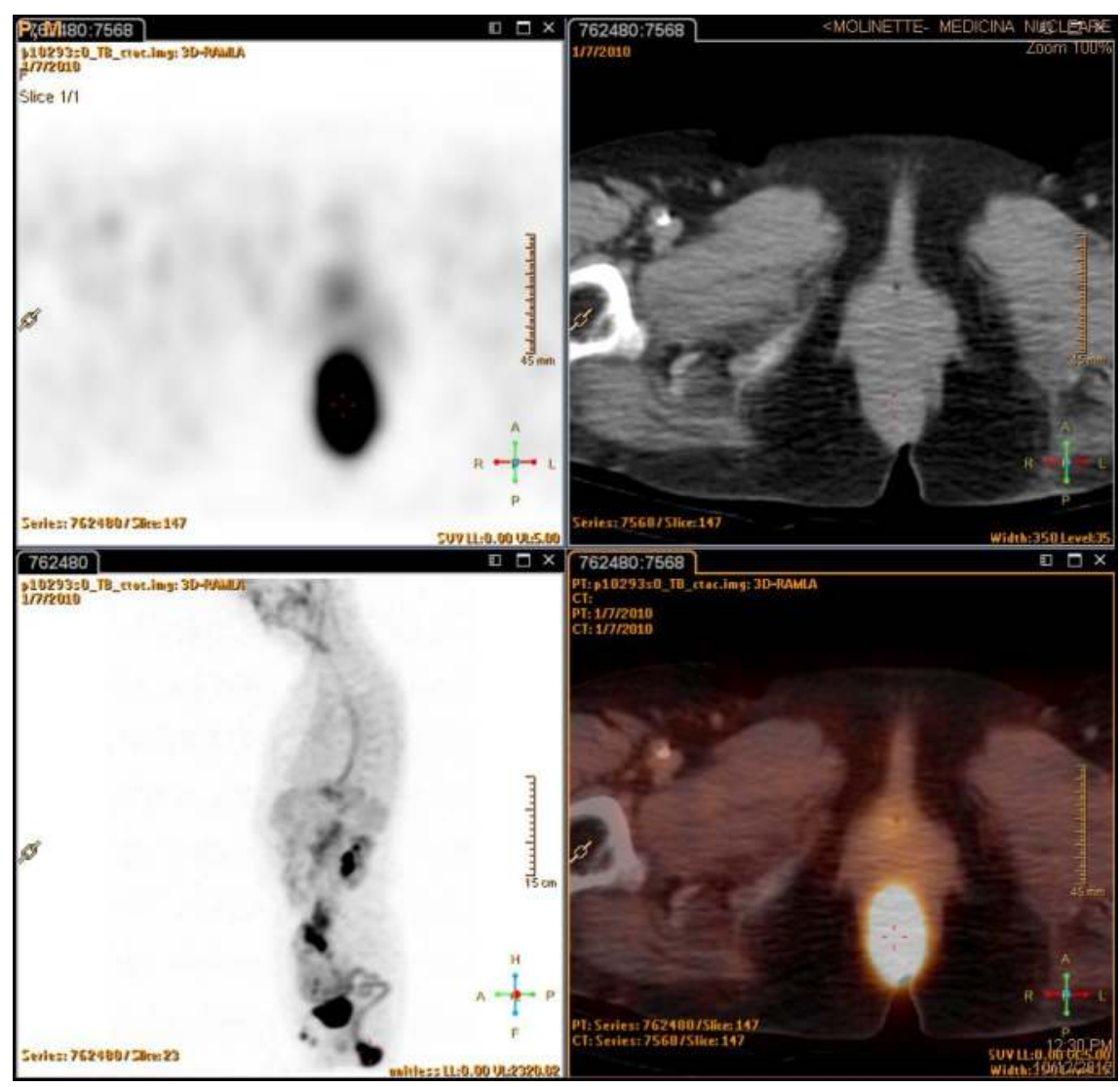

Figure 1. PET-CT positive for anal cancer. 


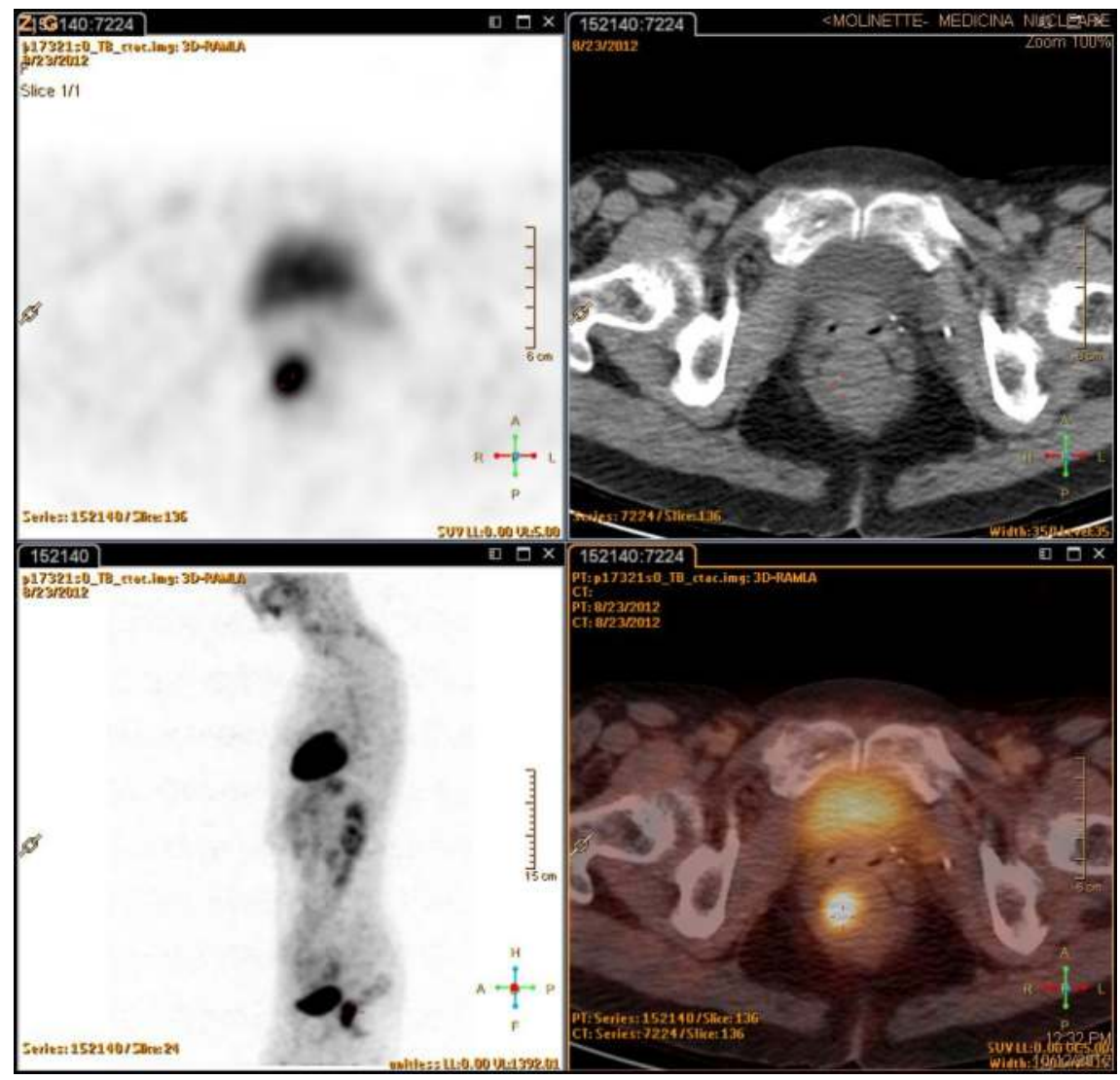

Figure 2. PET-CT positive for anal cancer.

\section{Detection of perirectal and pelvic nodes}

Perirectal and/or pelvic nodes were revealed by PET-CT in $4.5-67 \%$ and by CT-scan in $13.6-49 \%$ of patients. In all the reported series, except the one of Bannas and Coll [47], PET-CT evidentiated more perirectal and pelvic nodes vs CT-scan

Results are repoted in Table 2 [34-54]. Figure 3 present a case of PET-CT positive for perirectal lymph nodes metastases. 


\begin{tabular}{|c|c|c|c|}
\hline Author, year & $\begin{array}{l}\text { Patients } \\
\text { (Total) }\end{array}$ & Incidence PET-CT & Incidence CT scan \\
\hline Trautmann, 2005 & 21 & $9 / 21(42.8 \%)$ & n.r. \\
\hline Cotter, 2006 & 41 & $9 / 41(22 \%)$ & $8 / 41$ (20\%) \\
\hline Piperkova, 2006 & 1 & $1 / 1(100 \%)$ & n.r. \\
\hline Anderson, 2007 & 3 & $1 / 3(33.3 \%)$ & n.r. \\
\hline Schwarz, 2008 & 53 & n.r. & n.r. \\
\hline Nguyen, 2008 & 48 & 9/48 (19\%) & 7/38 (18\%) \\
\hline lagaru, 2009 & 8 & $2 / 8(20 \%)$ & n.r. \\
\hline de Winton, 2009 & 61 & 41/61 (67\%) & 30/61 (49\%). \\
\hline Forrest, 2009 & 39 & n.r. & n.r. \\
\hline Renaud, 2009 & 20 & $12 / 20(60 \%)$ & n.r. \\
\hline Kidd, 2010 & 77 & $8 / 77(10.4 \%)$ & n.r. \\
\hline Krengli, 2010 & 27 & n.r. & n.r. \\
\hline Bannas, 2010 & 22 & 2/17 (11.7\%) & $3 / 22(13.6 \%)$ \\
\hline Engledow, 2010 & 40 & n.r. & n.r. \\
\hline Vercellino, 2011 & 22 & $1 / 22(4.5 \%)$ & n.r. \\
\hline Sveistrup, 2012 & 91 & 28/91 (30.7\%) & n.r. \\
\hline Mistrangelo, 2012 & 53 & 14/53 (26.4\%) & $7 / 40$ (17.5\%) \\
\hline Wells, 2012 & 30 & n.r. & n.r. \\
\hline Bhuva, 2012 & 43 & n.r. & n.r. \\
\hline
\end{tabular}

n.r.: Not Reported

Table 2. Incidence of perirectal and pelvic metastases in lymph nodes

\section{Detection of inguinal lymph nodes}

PET/CT was positive for inguinal metastases in $0-37 \%$ of patients, while CT scan in $7.4-41 \%$ of them. Mistrangelo et Al [49] compared PET-CT with sentinel lymph node biopsy (SNB) of inguinal nodes in 41 cases. Their findings showed that SNB confirmed the presence of inguinal metastases in only 8 cases, with 4 of 41 patients (9.7\%) false positive and 2 of 41 patients $(4.9 \%)$ false negative. Comparison between SNB and CT findings (34 patients) showed that SNB identified 4 of 34 patients $(11.7 \%)$ false positive and 4 of 34 patients $(11.7 \%)$ false negative patients. This is the only paper, to our knowledge, that compares the 2 techniques. 


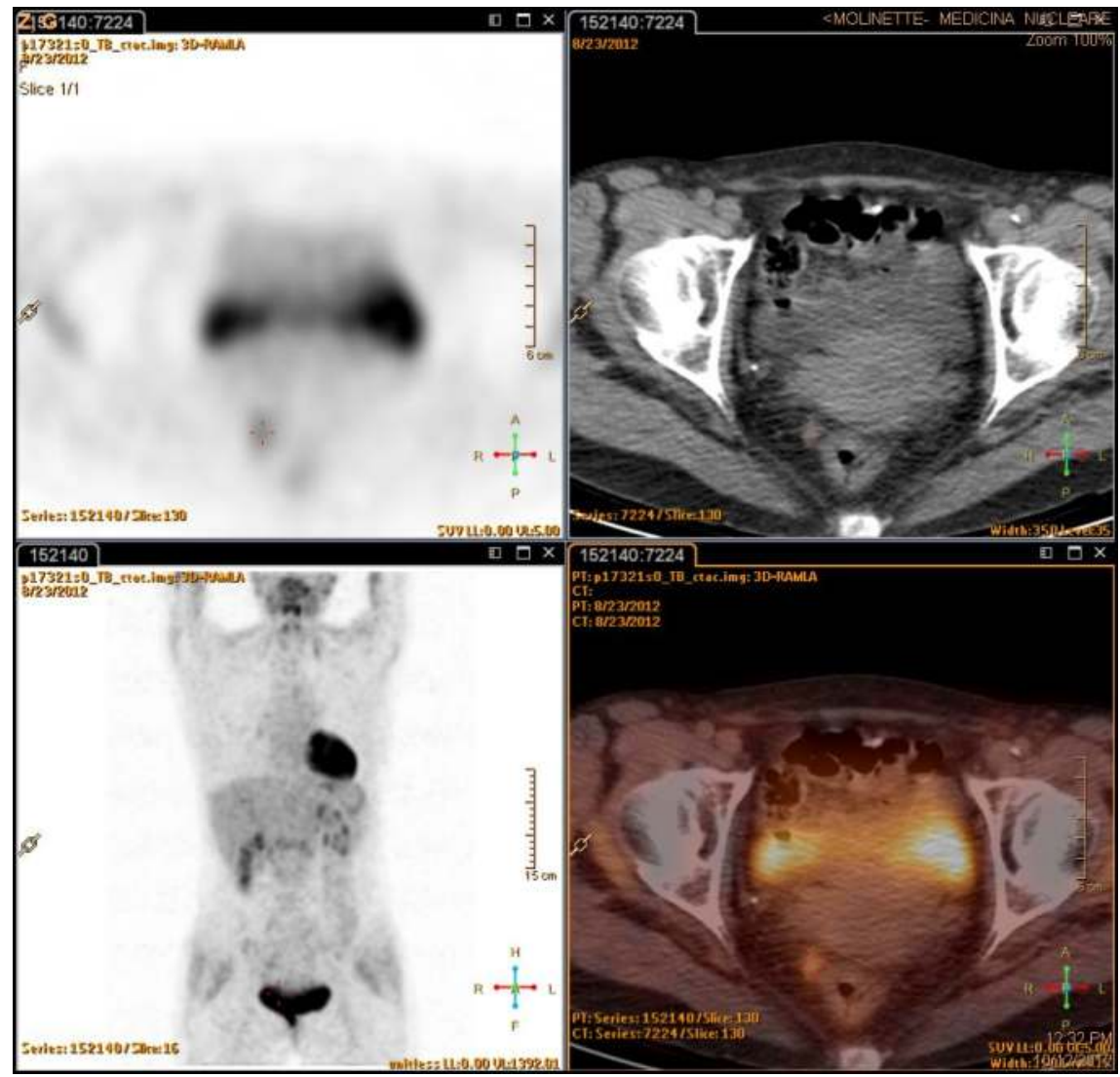

Figure 3. PET-CT positive for perirectal lymph nodes metastases.

Cotter and colleagues compared CT and physical examination to 18F-FDG PET/CT in the staging of carcinoma of anal canal, particularly of the inguinal nodal involvement [35]. They enrolled 41 consecutive patients with biopsy proved anal cancer and studied them with physical examination, CT scan and PET-CT scan. PET-CT scans described nodal groin positivities in 15 patients (37\%); CT documented abnormal nodes in 9 subjects (22\%). Particularly, $20 \%$ of CT-negative groins were PET positive, leading to upstaging in 8 of the 32 patients (25\%). Furthermore, 3 of 13 CT-positive groins were PET-negative (23\%) [35]. About 23\% of clinically negative groins were PET-positive, leading to upstaging in 9 of the 32 subjects without clinical inguinal nodal involvement. Moreover, about $17 \%$ of inguinal stations negative by both CT and physical exam were PET-positive, allowing for upstaging in each of 
these cases. Ten of 18 inguinal stations (56\%) positive by either physical examination or CT, but not both, were positive by PET. Moreover, all four groins positive by both CT and physical examination were positive by PET [35]. Autors concluded that PET-CT documented more abnormal inguinal nodes than $\mathrm{CT}$ or physical examination and they explained that cancer nodal metastases occur in node $<5 \mathrm{~mm}$ in size, below the limit of detection by CT or physical exam; instead, FDG-PET scan detects pathological sites by differential glucose intake rather than limph node morphology; so that, PET is able in detecting little nodal metastases, but no micrometastases.

Results are repoted in Table 3 [34-54]. Figures 4 and 5 present a case of PET-CT positive for inguinal lymph nodes metastases.

\begin{tabular}{|c|c|c|c|}
\hline Author, year & $\begin{array}{l}\text { Patients } \\
\text { (Total) }\end{array}$ & Incidence PET-CT & Incidence CT scan \\
\hline Trautmann, 2005 & 21 & $0 / 21(0 \%)$ & n.r. \\
\hline Cotter, 2006 & 41 & 15/41 (37\%) & 9/41 (22\%) \\
\hline Piperkova, 2006 & 1 & $0 / 1(0 \%)$ & n.r. \\
\hline Anderson, 2007 & 3 & $0 / 3(0 \%)$ & n.r. \\
\hline Joon, 2007* & 48 & n.r. & n.r. \\
\hline Schwarz, 2008 & 53 & n.r. & n.r. \\
\hline Nguyen, 2008* & 48 & $8 / 48(16.6 \%)$ & n.r. \\
\hline lagaru, 2009 & 8 & $1 / 8(12.5 \%)$ & n.r. \\
\hline de Winton, 2009 & 61 & $6 / 61(10 \%)$ & 9/61 (15\%). \\
\hline Forrest, 2009 & 39 & n.r. & n.r. \\
\hline Renaud, 2009 & 20 & $5 / 20(25 \%)$ & $4 / 20(20 \%)$ \\
\hline Kidd, 2010 & 77 & $6 / 77(7.8 \%)$ & n.r. \\
\hline Krengli, 2010 & 27 & $3 / 27(11.1 \%)$ & $2 / 27(7.4 \%)$ \\
\hline Bannas, 2010 & 22 & $6 / 22(27 \%)$ & $9 / 22(41 \%)$ \\
\hline Engledow, 2010 & 40 & $9 / 40(22.5 \%)$ & $0 / 40(0 \%)$ \\
\hline Vercellino, 2011 & 22 & $3 / 22$ (13.6\%) & n.r. \\
\hline Sveistrup, 2012 & 91 & $41 / 91$ (45\%) & n.r. \\
\hline Mistrangelo, 2012 & 53 & $12 / 53(22.6 \%)$ & $8 / 40(20 \%)$ \\
\hline Wells, 2012 & 30 & n.r. & n.r. \\
\hline Bhuva, 2012 & 43 & $7 / 43$ (16.3\%) & n.r. \\
\hline
\end{tabular}

PS: * The 2 papers were published separately considering the same series.

n.r.: Not Reported

Table 3. Incidence of metastases in inguinal lymph nodes 


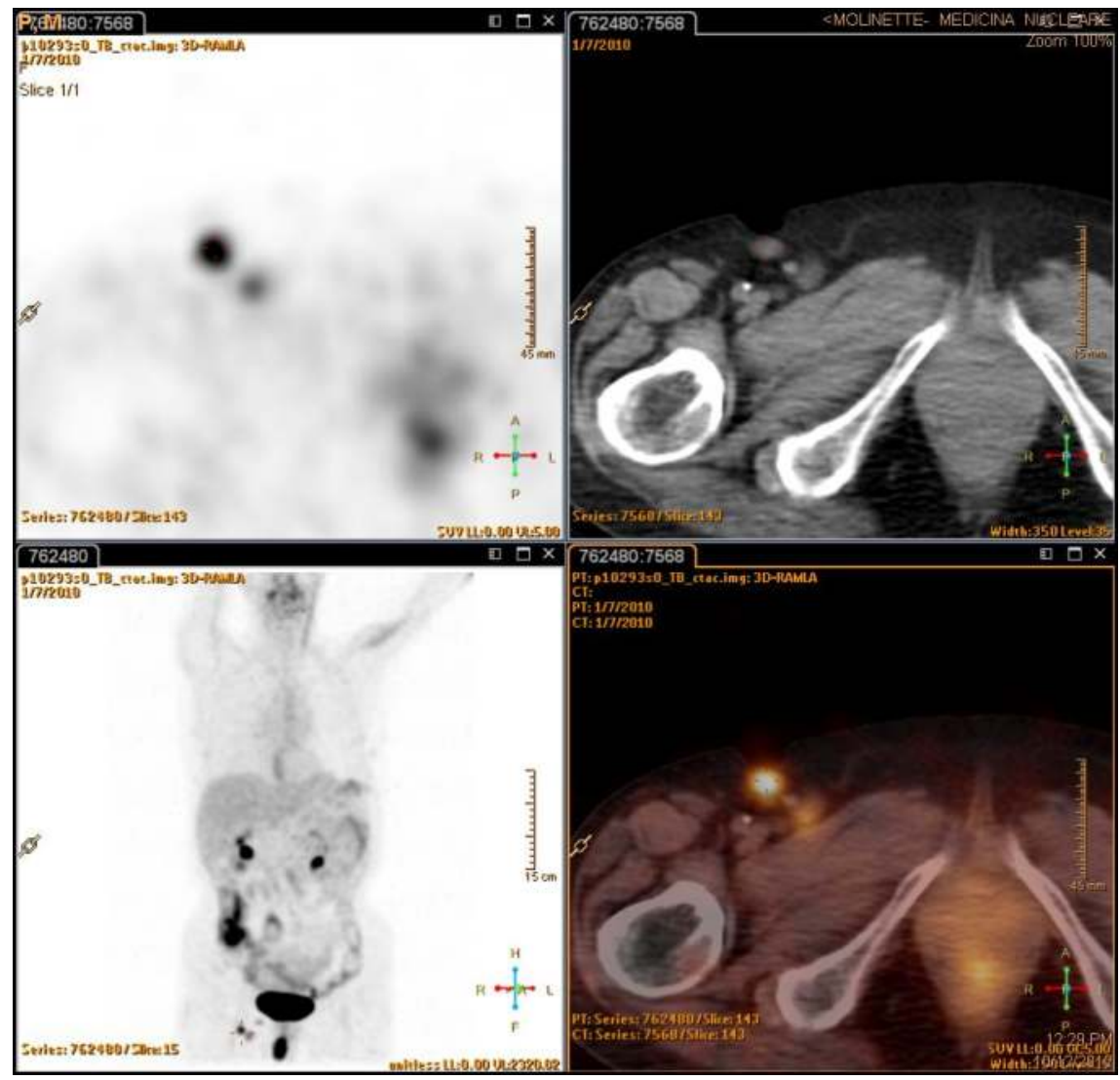

Figure 4. PET-CT positive for inguinal lymph nodes metastases. 


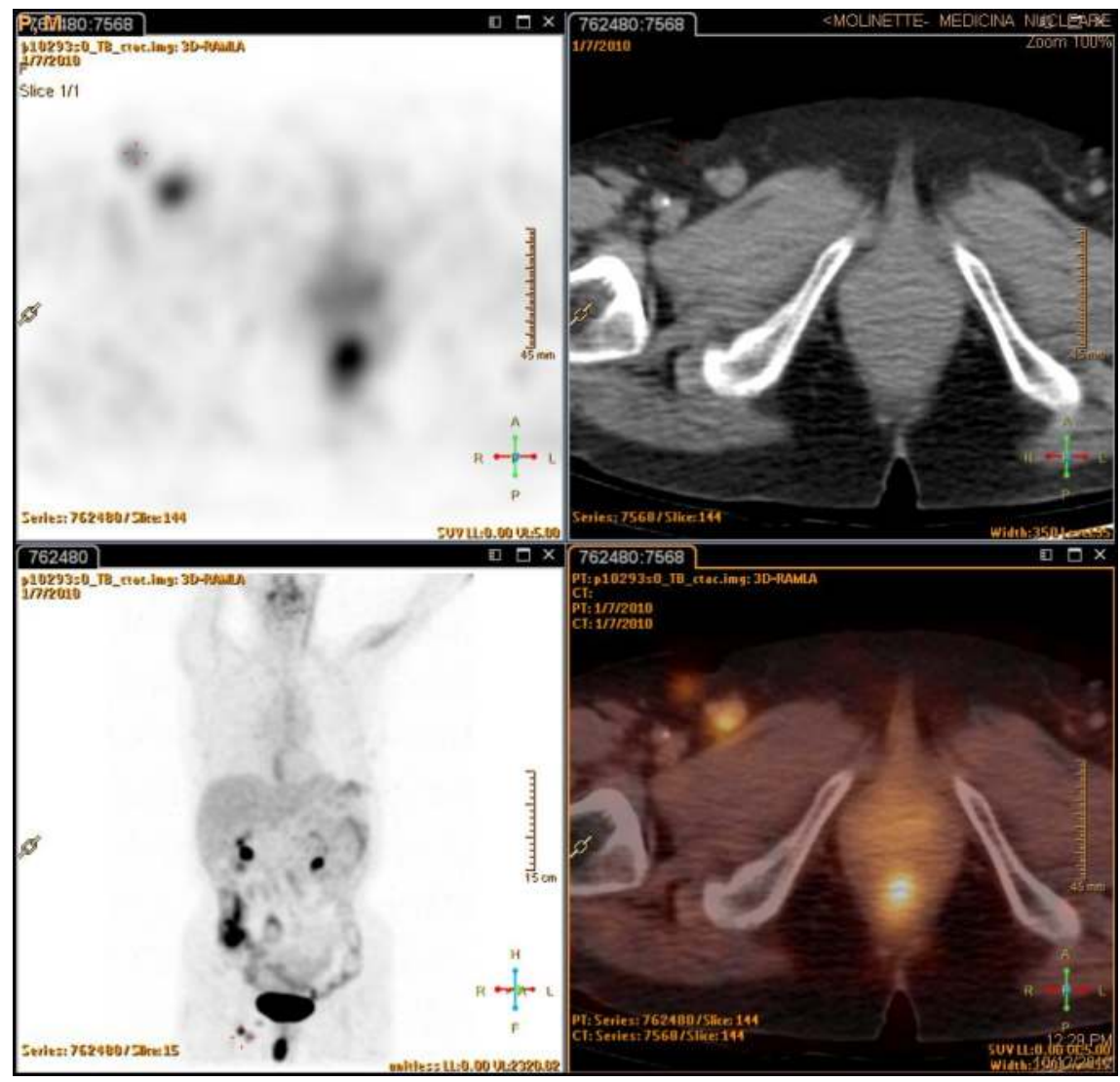

Figure 5. PET-CT positive for inguinal lymph nodes metastases.

\section{Pre-treatment final staging}

In the published series tumors were staged according to the American Joint Committee on Cancer staging system [22]. PET/CT upstaged $9-100 \%$ and dowstaged $0-25 \%$ of patients studied. The radiation fields changed in $3.7-33.3 \%$ of cases.

Results are repoted in Table 4 [34-54]. 


\begin{tabular}{|c|c|c|c|c|c|}
\hline Author, year & $\begin{array}{l}\text { Patients } \\
\text { (Total) }\end{array}$ & Upstaging & Downstaging & Invariate & Change RT planes \\
\hline Trautmann, 2005 & 21 & $10 \%$ & n.r. & $90 \%$ & n.r. \\
\hline Cotter, 2006 & 41 & $17 \%$ & n.r. & $83 \%$ & n.r. \\
\hline Piperkova, 2006 & 1 & $100 \%$ & 0 & 0 & n.r. \\
\hline Anderson, 2007 & 3 & $33.3 \%$ & n.r. & $66.6 \%$ & $33.3 \%$ \\
\hline Joon, 2007* & 48 & $17 \%$ & $6 \%$ & $77 \%$ & $19 \%$ \\
\hline Schwarz, 2008 & 53 & n.r. & n.r. & n.r. & n.r. \\
\hline Nguyen, 2008* & 48 & $17 \%$ & $6 \%$ & $77 \%$ & $19 \%$ \\
\hline lagaru, 2009 & 8 & n.r. & n.r. & n.r. & n.r. \\
\hline de Winton, 2009 & 61 & $15 \%$ & $8 \%$ & $77 \%$ & $13 \%$ \\
\hline Forrest, 2009 & 39 & n.r. & n.r. & n.r. & n.r. \\
\hline Renaud, 2009 & 20 & $15 \%$ & n.r. & $85 \%$ & n.r. \\
\hline Kidd, 2010 & 77 & n.r. & n.r. & n.r. & n.r. \\
\hline Krengli, 2010 & 27 & $18.5 \%$ & $0 \%$ & $81.5 \%$ & $3.7 \%$ \\
\hline Bannas, 2010 & 22 & $9 \%$ & $18 \%$ & $73 \%$ & $23 \%$ \\
\hline Engledow, 2010 & 40 & n.r. & n.r. & n.r. & $12.5 \%$ \\
\hline Vercellino, 2011 & 22 & n.r. & n.r. & n.r. & $20 \%$ \\
\hline Sveistrup, 2012 & 91 & $14 \%$ & n.r. & $86 \%$ & $17 \%$ \\
\hline Mistrangelo, 2012 & 53 & $37.5 \%$ & $25 \%$ & $37.5 \%$ & $12.6 \%$ \\
\hline Wells, 2012 & 30 & $17 \%$ & $19 \%$ & $65 \%$ & $29 \%$ \\
\hline Bhuva, 2012 & 43 & $30.2 \%$ & $11.6 \%$ & $58.2 \%$ & n.r. \\
\hline
\end{tabular}

PS: * The 2 papers were published separately considering the same series.

n.r.: Not Reported

Table 4. Upstaging and downstaging of PET-CT respect CT scan

\begin{tabular}{ccccc}
\hline Author, year & $\begin{array}{c}\text { Patients } \\
\text { (Total) }\end{array}$ & Recurrences at PET-CT & FP & FN \\
\hline Trautmann, 2005 & 21 & $12 / 18(66.6 \%)$ & $9 / 12(75 \%)$ & $2 / 6(33.3 \%)$ \\
\hline Mistrangelo, 2012 & 53 & $10 / 43(23.2 \%)$ & $6 / 10(60 \%)$ & $0 / 33(0 \%)$ \\
\hline
\end{tabular}

Table 5. Follow up at 1 month 


\begin{tabular}{ccccc}
\hline Author, year & $\begin{array}{c}\text { Patients } \\
\text { (Total) }\end{array}$ & Recurrences at PET-CT & FP & FN \\
\hline Schwarz, 2008 & 53 & $9 / 53(17 \%)$ & $2 / 9(22.2 \%)$ & n.r. \\
\hline Nguyen, 2008 & 48 & $5 / 25(20 \%)$ & $3 / 5(60 \%)$ & n.r. \\
\hline lagaru, 2009 & 8 & $1 / 6(16.6 \%)$ & n.r. \\
\hline Forrest, 2009 & 39 & $13 / 39(33.3 \%)$ & $4 / 13(30.7 \%)$ & n.r. \\
\hline Renaud, 2009 & 20 & $6 / 11(54.5 \%)$ & $2 / 6(33.3 \%)$ & $0 / 5(0 \%)$ \\
\hline Vercellino, 2011 & 77 & $14 / 59(14 \%)$ & $n . r$. & $1 / 18(5.5 \%)$ \\
\hline Mistrangelo, 2012 & 22 & $18 / 36(50 \%)$ & $4 / 18(22.2 \%)$ & $0 / 32(0 \%)$ \\
\hline
\end{tabular}

n.r.: Not Reported

Table 6. Follow up at 3 months

\subsection{Follow-up}

Few papers report the results of follow up in patients submitted to combined radiochemotherapy for anal cancer with PET-CT. Moreover PET-CTs of follow up were scheduled differently. This aspect does not permit an adequate comparison between various series.

\subsection{Follow-up at 1 month}

Only two papers reported the results of follow up with PET/CT performed 1 month after the end of combined radiochemotherapy [34,49]. Recurrences are reported respectively in 66.6 and $23.2 \%$ of cases. When follow up is analyzed Trautmann [34] reported $75 \%$ of false positive (FP) and $33.3 \%$ of false negative (FN), while Mistrangelo [49] revealed $60 \%$ of FP and none FN. The follow up period was over 18 months in the first study, and 20.3 months in the other one.

Mistrangelo et $\mathrm{Al}$ compared also the results of PET-CT with anal biopsy: in the detection of persistence of disease, PET/CT had a sensitivity of $66.6 \%$, a specificity of $92.5 \%$, a positive predictive value (PPV) of $40 \%$ and a negative predictive value (NPV) of $97.4 \%$, while anal biopsy had a sensitivity of $100 \%$, a specificity of $97.5 \%$, a PPV of $75 \%$ and a NPV of $100 \%$ [49].

\subsection{Follow-up at 3 months}

The value of PET-CT performed 3 months after combined radiochemotherapy for anal cancer was analyzed in only 8 papers. Recurrences were reported in $4.6-54.5 \%$ of cases [39-41, 43-45, 49-50]. False positive were reported in $22.2-62.5 \%$, while FN in $0-5.5 \%$ of cases. 
Mistrangelo et $\mathrm{Al}$ compared results with anal biopsy: in the detection of recurrence of disease, PET/CT had a sensitivity of $100 \%$, a specificity of $97.4 \%$, a PPV of $66 \%$ and a NPV of $100 \%$. Anal biopsy had a sensitivity of $100 \%$, a specificity of $100 \%$, a PPV of $100 \%$ and a NPV of $100 \%$ [49].

\section{Discussion}

Anal cancer is a relatively uncommon tumor, but its incidence increased over the last decades. Accurate clinical staging is important for prognostic information, for planning the radiotherapy target volume and for defining therapeutic dose. An accurate evaluation of disease extent can help to individualized radiotherapy planning, ensuring the accurate coverage of disease and sparing of organs at risk. If inguinal node metastasis are known, the radiation plan must include a radiation boost to the groin, but these increased radiation doses are associated with acute and late toxicity, like chronic lymph oedema and femoral neck fracture [47].

Since 2005, the use of PET/CT in anal cancer has been described [34-55], but a medline research about the use of PET/CT and anal cancer management shows a relatively little amount of studies. As suggested by Grigsby et al., the advantage of FDG-PET/CT is that it can address all three staging criteria of the TNM system in a single whole-body imaging procedure: demonstrate the extent of the primary tumor, detect lymph node metastases, and reveal any sites of distant metastases [55]. The 2007 National Comprehensive Cancer Network treatment guidelines included PET/CT as a part of the standard pre-treatment workup of patients diagnosed with anal carcinoma [56]. The new version 2.2012 consider PET-CT scan for work up, even if its use for staging or treatment planning has not been validated [57]. The Authors suggest that PET-CT actually does not replace a diagnostic CT scan [57].

Otherwise accurate staging of anal cancer followed by optimal planning of combined radiochemotherapy treatment can extend patient survival. Anatomical imaging techniques such as $\mathrm{CT}$ and MRI cannot evaluate tumor biology and behavior. PET/CT imaging is increasingly used to stage different malignant diseases [59]. The advantage of PET/CT fusion imaging resides in its ability to correlate findings from anatomic and functional imaging modalities, lending it a more important role than diagnostic CT alone in the selection of proper treatment [36]. Moreover, therapy-induced changes in tumors are related to changes in 18F-FDG uptake, and treatment response can be efficiently monitored by PET/CT also considering the standardized uptake value (SUV) of 18F-FDG.

Evidence from published data and our study [41] indicates that PET/CT is clearly superior to CT in visualizing the biopsy-proven primary tumor $(87.5-100 \%$ vs $47-75 \%)$, although the lack of sensitivity did not affect treatment. Otherwise both PET/CT and CT were unable to detect residual tumor after surgical excision.

Considering the results of staging anal cancer with PET-CT respect other classical staging tools, pre-treatment PET/CT upstaged $9-37.5 \%$ and downstaged $0-25 \%$ of patients with anal cancer 
[34-54]. PET/CT at diagnosis can also be used for radiation therapy treatment planning as it clearly defines sites of metabolically active tumor [47].

Radiation treatment fields changed in 3.7-33.3\% of patients [37-38, 40, 42, 46-52]. Only Vercellino et al. [50] reported no change in treatment fields in their series of 44 patients.

In the majority of studies, upstaging was related to a suggested better staging of metastases in perirectal, pelvic and inguinal lymph nodes. As it defines nodal and metastatic disease, PET imaging can improve the staging of anal cancer [40].

Mai and Coll assumed that PET positive lymph nodes in a setting of anal cancer as defined by SUV uptake raise the likelihood of lymph node involvement, which would warrant more aggressive treatment in patients with PET positive nodes [60].

The sensitivity of $\mathrm{CT}$ for detecting nodal metastases in the pelvic and inguinal region is limited to $40-68 \%$ [25]. By contrast, PET/CT showed a higher specificity (80-90\%) and sensitivity (70-90\%) in the detection of nodal and distant metastases for several tumor types like nonsmall-cell lung cancer and head and neck cancer [25]. Also in gynecologic cancer, PET can have a specificity of $90-95 \%$.

Cotter et al. [35] reported that PET/CT upstages inguinal nodes in $17 \%$ of patients. They also found a higher rate of PET/CT positive for inguinal metastases in HIV-seropositive versus HIV-seronegative patients (44\% vs. 16\%), while other Authors observed only a marginal difference in positive inguinal metastases between these two patient subgroups (28.5\% vs. $25 \%)$ [49].

Otherwise some $5 \%$ of inguinal lymph node metastases detected with PET/CT are FP at fineneedle aspiration cytology (FNAC) [48] and up to 57\% at histological confirmation of samples from sentinel node biopsy (SNB) [61]. Iagaru [41] and Engledow [48] reported that inguinal lymph nodes positive at PET/CT were negative at FNAC in 50\% and at SNB in 5\% of cases. Therefore, positive lymph nodes identified by PET/CT should be adequately studied with biopsy before changing radiotherapy plans. In this connection, the high incidence of inguinal metastases found on imaging as compared with conventional staging tools should warn against unnecessary inguinal radiotherapy. Inguinal staging with SNB may explain the lower percentage of change in radiotherapy fields in ours series compared to others.

PET/CT was recently considered also for follow-up of patients undergoing radio- and chemotherapy treatment in anal cancer. Kidd et al. [45] reported that a higher $\mathrm{SUV}_{\max }$ was associated with lymph node involvement at diagnosis. These patients were also at higher risk of persistent disease on their post-treatment PET, if the study was performed less than 4 months after completing therapy. The authors go on to suggest that $\mathrm{SUV}_{\max }$ for FDG represents a potential new biomarker for anal cancer prognosis, as it is significantly associated with lymph node involvement at diagnosis, treatment response, and disease-free survival [45].

Post-treatment PET/CT is indicated to determine response to therapy and it is highly predictive of long-term clinical outcomes [55]. It can also be used to evaluate sites of recurrent disease. Few studies have examined clinical response to therapy, and clinical workup differs widely. 
Piperkova et al. suggested that PET/CT in anal cancer accurately identifies treatment response [36]. Schwarz et al. [39] reported that posttherapy FDG response was the most significant predictor of progression-free survival $(\mathrm{P}=0.0003)$ and that it was more predictive of the treatment outcome than either pre-treatment tumor size $(\mathrm{P}=0.08)$ or nodal status $(\mathrm{P}=0.40)$. Persistent disease is indeed a predictor of poor clinical outcome [39].

Mistrangelo et $\mathrm{Al}[49]$ reported that PET/CT assessment at 1 month had a sensitivity of $66.6 \%$, a specificity of $92.5 \%$, a PPV of $40 \%$ and a NPV of $97.4 \%$ for detecting persistence of anal disease. These data are not comparable to previous observations. Only Trautmann et al. [34] reported on the results of PET/CT assessment at 1 month (persistence of disease of $66.6 \%$ of cases), suggesting that PET/CT at 1 month after the end of therapy is of little value in predicting the durability of response.

In contrast, anal biopsy at 1-month follow-up had higher sensitivity and specificity than PET/ $\mathrm{CT}$, even if assessment with biopsy of non-progressive residual tumor at 1 month after treatment may be misleading as shortly after radiation nonviable cancer cell may look morphologically intact [62].

Considering these aspects biopsy for a non-progressive residual tumor at 1 month after treatment shoud not be taken as this can lead to unnecessary abdominoperineal excision. These patients should be closely observed.

Mistrangelo et $\mathrm{Al}$ reported that PET/CT assessment at 3 months had a sensitivity of $100 \%$, a specificity of $97.4 \%$, a PPV of $66 \%$ and a NPV of $100 \%$; anal biopsy had the same sensitivity but a better specificity than PET/CT [49]. Vercellino and Coll [50] reported thet sensitivity, specificity and negative predictive value of PET-CT for the detection of recurrent locoregional disease is $93 \%, 81 \%$ and $94 \%$ respectively, resulting in an impact on management in $20 \%$.

\section{Conclusions}

The role of PET-CT in the evaluation of anal cancer is evolving. PET/CT detect the primary tumor more often than $\mathrm{CT}$, but neither tool is indicated to reveal persistent disease after surgery. PET/CT proved useful in initial staging perirectal/pelvic or inguinal lymph nodes. PET/CT can document also unknown metastases, changing the disease stadiation. However, upstaging related to lymph nodes metastases might have been overestimated, as up to $31 \%$ of inguinal metastases identified by PET/CT are reportedly false positive, but metabolic imaging can descover little nodal metastases, too little for CT and clinical evaluation. Currently, inguinal lymph nodes are better staged by sentinel node biopsy. PET/CT assessment at 1month follow-up had lower sensitivity and specificity than anal biopsy.

PET/CT assessment at 3 months more accurately evaluated the persistence or the recurrence of anal disease and thus allowed for better follow up when combined with anal biopsy. 


\section{Author details}

Massimiliano Mistrangelo ${ }^{1 *}$ and Adriana Lesca ${ }^{2}$

*Address all correspondence to: mistrangelo@katamail.com

1 Digestive and Colorectal Surgical Department, Centre of Minimal Invasive Surgery, University of Turin, Città della Salute e della Scienza Hospital, Italy

2 Department of Nuclear Medicine, Città della Salute e della Scienza Hospital, Italy

\section{References}

[1] Nivatvongs S. Perianal and Anal Canal Neoplasms. In Principles and Practice of Surgery for the Colon, Rectum and Anus. Ed. Quality Medical Publishing, Inc. St Louis Missouri. 1999: 447-471.

[2] Morson BC, Sobin LH. Histological typing of intestinal tumours. In International Histological Classification of Tumors, No 15. Geneva: World Health Organization 1976.

[3] Cummings BJ, Keane TJ, OSullivan B, Wong CS, Catton CN. Epidermoid anal cancer: treatment by radiation alone or by radiation and 5-fluorouracil with and without mitomycin C. Int J Rad Oncol Biol Phys 1991; 21:1115-25.

[4] Greene FL, Page DL, Fleming ID et Al eds. American Joint Committee on Cancer: AJCC Cancer Staging Manual. 6th ed, New York, NY, USA: Springer 2001; 157-164.

[5] Ries LAG., Harkins D., Krapcho M., et al. Edwards BK. (eds). SEER Cancer Statistics Review, 1975-2003. Baltimore, MD: National Cancer Institute, 2005: 1-103.

[6] Siegel R., Ward E., Brawley O., Jemal A. Cancer statistics, 2011. The impact of eliminating socioeconomic and racial disparities on premature cancer deaths. CA Cancer J Clin 2011; 61: 212-236.

[7] Clark MA, Hartley A, Geh JI. Cancer of the anal canal. Lancet Oncol 2004; 5:149-157.

[8] Klas J, Rothenberger D, Wong WD, Madoff R. Malignant tumors of the anal canal. The spectrum of disease, treatment and outcome. Cancer 1999; 85:1686-1693.

[9] Minsky BD, Hoffman JP, Kelsen DP. Cancer of the anal region. In: DeVita Jr VT, Hellman S, Rosenberg SA, eds. Cancer: Principles \& Practice of Oncology, Sixth Edition. Philadelphia: Lippincott-Williams \& Wilkins, 2001: 1319-1342.

[10] Deans GT, McAleer JJA, Spence RAJ. Malignant anal tumours. Br J Surg 1994; 81: 500-508. 
[11] Ryan D, Compton C, Mayer R. Carcinoma of the anal canal. N Engl J Med 2000; 342:792800.

[12] Frisch M, Fenger C, van den Brule AJ, et al. Variants of squamous cell carcinoma of the anal canal and perianal skin and their relation to human papilloma viruses. Cancer Res Feb 1999; 1;59:753-7.

[13] Holmes F, Borek D, Owen-Kummer M, et al. Anal cancer in women. Gastroenterology 1988; 95:107-11.

[14] Ryan DP, Mayer RJ. Anal carcinoma: histology, staging, epidemiology, treatment. Curr Opin Oncol 2000; 12: 345-52.

[15] Beckmann AM, Daling JR, Sherman KJ, et al. Human papillomavirus infection and anal cancer. Int J Cancer 1989; 43:1042-49.

[16] Williams GR, Talbot IC. Anal carcinoma: a histological review. Histopathology 1994; 25:507-16.

[17] Palmer JG, Scholefield JH, Coates PJ, et al. Anal cancer and human papillomaviruses. Dis Colon Rectum 1989; 32:1016-22.

[18] Daling JR, Madeleine MM, Johnson LG et al. Human papillomavirus, smoking, and sexual pratices in the etiology of anal cancer. Cancer 2004;101:270-280.

[19] Hope E. Uronis, Johanna C Bendell. Anal Cancer: an overview. The Oncologist 2007;12:524-534.

[20] Salmo E., Haboubi N. Anal Cancer: Pathology, Staging and Evidence-based minimum data set. Colorectal Dis 2011; 13 (Suppl 1): 11-20.

[21] Stearns MW., Urmacher C., Sternberg SS. Cancer of the anal canal. Cur Probl Cancer 1980; 4: 1-44.

[22] Golden GT., Horsley JS. Surgical management of epidermoid carcinoma of the anus. Am J Surg 1976; 131: 275-280.

[23] Nigro N.D., Vaitkeicus V.K., Basil Considine B.: Combined therapy for cancer of the anal canal: a preliminary report. Dis Colon Rectum 1974; 17 (3): 354-356.

[24] Gerard J-P, Chapet O., Samiei F., Morignat E., Isaac S., Paulin C., Romestaing P., Favrel V., Mornex F., Bobin J-Y.: Management of inguinal lymph node metastases in patients with carcinoma of the anal canal. Experience in a series of 270 patients treated in Lyon and review of the Literature. Cancer 2001; 92: 77-84.

[25] Bartelink H., Roelofsen F., Eschwege F., et al. Concomitant radiotherapy and chemotherapy is superior to radiotherapy alone in the treatment of locally advanced anal cancer: results of a phase III randomized trial of the European Organization for Research and Treatment of Cancer Radiotherapy and Gastrointestinal Cooperative Groups. J Clin Oncol 1997; 15 (5): 2040-2049. 
[26] Al B. Benson III, J Pablo Arnoletti et al. Anal Carcinoma, Version 2.2012: Featured Uptades to the NCCN Guidelines. J Nat Compr Canc Netw 2012;10:449-454

[27] Czito BG, Willet CG, Current management of anal cancer. Curr Oncol Rep 2009;11(3): 186-92.

[28] Cotter SE., Perry W Grigsby et al. FDG-PET/CT in the evaluation of anal carcinoma. Int J Radiation Onc Biol Phys 2006; 65 (3): 720-725.

[29] Jaiyesimi IA, Pazdur R. Cisplatin and 5-fluorouracil as salvage therapy for recurrent metastatic squamous cell carcinoma of the anal canal. Am J Clin Oncol 1993;16:563-540.

[30] Evans TR, Mansi JL Glees JP. Response of metastatic anal carcinama to single agent carboplatin. Clin Oncol (R Coll Radiol) 1993;5:57-58.

[31] Fisher WB, Herbst KD, Sims JE et al. Metastatic cloacogenic carcinoma of the anus: sequential responses to adriamycin and cis-dichlorodiammineplatinum (II). Cancer Treat Rep 1978;62:91-97.

[32] Zimm S, Wampler GL. Response of metastatic cloacogenic carcinoma to treatment with semustine. Cancer 1981;48:2575-2576.

[33] Walk PE, Bailey DL et al Positron Emission Tomography - Basic science and clinical practice. Ed. Springer.

[34] Trautmann TG, Zuger JH. Positron emission tomography for pre-treatment staging and posttreatment evaluation in cancer of the anal canal. Mol Imaging Biol 2005; 7: 309-313.

[35] Cotter SE., Grigsby PW, Siegel BA, Dehdashti F., Malyapa RS., Fleshman JW., Birnbaum EH., Wang X., Abbey E., Tan B., Kodner IJ., Hunt SR., Lowney JK., Mutch MG., Dietz DW., Myerson RJ. FDG-PET/CT in the evaluation of anal carcinoma. Int J Radiat Oncol Biol Phys 2006; 65: 720-725.

[36] Piperkova E., Raphael B., Altinyay M., et al. Impact of PET/CT on initial staging, restaging and treatment management of anal cancer: a clinical case with literature review. J BUON 2006; 11: 523-527.

[37] Anderson C., Koshy M., Staley C., et al. PET-CT fusion in radiation management of patients with anorectal tumors. Int J Radiation Oncology Biol Phys 2007; 69 (1): 155-162.

[38] Joon Dl., Nguyen B., Khoo V., Joon ML., See A., Kai C., Chao M., Wada M., Feigen M., Quong G. PET in anal cancer: Its role in staging and evaluation after chemoradiation. Int J Radiation Oncology Biol Phys 2007; 69 (3): S296.

[39] Schwarz JK., Siegel BA., Dehdashti F., Myerson RJ., Fleshman JW., Grigsby PW. Tumor response and survival predicted by post therapy FDG-PET/CT in anal cancer. Int J Radiation Oncol Biol Phys 2008; 71 (1): 180-186. 
[40] Nguyen BT., Joon DL., Khoo V., Quong G., Chao M., Wada M., Joon ML., See A., Feigen M., Rykers K., Kai C., Zupan E., Scott A. Assessing the impact of FDG-PET in the management of anal cancer. Radiother Oncol 2008; 87: 376-382.

[41] Iagaru A., Kundu R., Jadvar H., Nagle D. Evaluation by 18 F-FDG-PET of patients with anal squamous cell carcinoma. Hell J Nucl Med 2009; 12 (1): 26-29.

[42] de Winton E., Heriot AG., Ng M., Hicks RJ., Hogg A., Milner A., Leong T., Fay M., Mackay J., Drummond E., Ngan SY. The impact of 18-fluorodeoxyglucose positron emission tomography on the staging, management and outcome of anal cancer. Br J Cancer 2009; 100: 693-700.

[43] Forrest W. FDG-PET/CT trumps CT in detecting anal carcinoma. AuntMinnie.com 2009.

[44] Renaud S., Guillermand S., Eberlé-Pouzeratte MC., Lemanski C., Faurous P., Artus JC. Apport de la tomographie par émission de positrons au ${ }^{18} \mathrm{~F}$-fluorodéoxyglucose (TEP-FDG) dans la prise en charge du cancer du canal anal. Med Nucl 2009; 33: 415-424.

[45] Kidd E., Dehdashti F., Siegel BA., Grigsby PW. Anal cancer maximum F-18 fluorodeoxyglucose uptake on positron emission tomography is correlated with prognosis. Radiother Oncol. 2010; 95; 288-291.

[46] Krengli M., Milia ME., Turri L.,Mones M., Bassi MC., Cannillo B., Deantonio L., Sacchetti G., Brambilla M., Inglese E. FDG-PET/CT imaging for staging and target volume delineation in conformal radiotherapy of anal carcinoma. Radiat Oncol 2010; 5: 10 .

[47] Bannas P., Weber C., Adam G., Frenzel T., Derlin T., Mester J., Klutmann S. Contrastenhanced $\left[{ }^{18} \mathrm{~F}\right]$ Fluorodeoxyglucose-positron emission tomography/computed tomography for staging and radiotherapy planning in patients with anal cancer. Int J Radiation Oncol Biol. Phys. 2011; 81: 445-451.

[48] Engledow AH., Skipworth JRA., Blackman G., Groves A., Bomanji J., Warren SJ., Ell PL., Boulos PB. The role of ${ }^{18}$ FDG PETCT in the clinical management of anal squamous cell carcinoma. Colorectal Dis 2011; 13: 532-537.

[49] Mistrangelo M., Pelosi E., Bellò M., Ricardi U., Milanesi E., Cassoni P., Baccega M. Filippini C., Racca P., Lesca A., Munoz FH., Fora G., Skanjeti A., Cravero F., Morino M. Role of positron emission Tomography-computed tomography in the management of anal cancer. Int J Radiat Oncol Biol Phys 2012; Sep 1: 84 (1): 66-72.

[50] Vercellino L., Montravers F., de Paredes V., Huchet V., Kerrou K., Bauer P., Touboul E., Talbot J-N. Impact of FDG PET/CT in the staging and the follow up of anal carcinoma. Int J Colorectal Dis 2011; 26: 201-210.

[51] Sveistrup J., Loft A., Berthelsen AK., Henriksen BM., Nielsen MB., Engelholm SA. Positron Emission Tomography/Computed Tomography in the staging and treatment of anal cancer. Int J Radiat Oncol Biol Phys 2012; 83: 134-141. 
[52] Wells IT., Fox BM. PET/CT in anal cancer - is it worth doing? Clinical Radiol 2012; 67: 535-540.

[53] Bhuva NJ., Glynne-Jones R., Sonoda L., Wong W-L., Harrison MK. To PET or not to PET? That is the question. Staging in anal cancer. Ann Oncol 2012; 23 (8): 2078-2082.

[54] Saboo SS., Zukotynski K., Shinagare AB., Krajewski KM., Ramaiya N. Anal carcinoma: FDG PET/CT in staging, response evaluation, and follow up. Abdom Imaging 2012; Sept 26 [Epub ahead of print], doi: 10.1007/s00261-012-9958-3.

[55] Grigsby PW. FDG-PET/CT: New horizons in anal cancer. Gastroenterol Clin Biol 2009; 33 (5): 456-458.

[56] Engstrom PF, Arnoletti JP, Benson AB 3rd, et al. NCCN clinical practice guidelines in oncology. Anal carcinoma. J Natl Compr Canc Netw 2010; 8 (1): 106-120.

[57] Benson AB 3rd, Arnoletti JP, Bekaii-Saab T. et Al. NCCN Clinical Practice Guidelines in Oncology: Anal Carcinoma. Version 2.2012: featured updates to the National Comprehensive Cancer Network guidelines. J Natl Compr Canc Netw 2012; 10: 449-454.

[58] American Joint Commission on Cancer. Anal Canal. In AJCC Cancer Staging Manual $6^{\text {th }}$ Ed. New York: Springer; 2002: 125-130.

[59] Ell PJ. PET/CT in oncology: a major technology for cancer. Chang Gung Med J. 2005; 28: 274-283.

[60] Mai SK., Welzel G., Hermann B., et al. Can the radiation dose to CT-enlarged but FDGPET-negative inguinal lymph nodes in anal cancer be reduced? Strahlenther Onkol 2009; 185: 254-259.

[61] Mistrangelo M., Pelosi E., Bellò M., Castellano I., Cassoni P., Ricardi U., Munoz F., Racca P., Contu V., Beltramo G., Morino M., Mussa A. Comparison of positron emission tomography scanning and sentinel node biopsy in the detection of inguinal node metastases in patients with anal cancer. Int J Radiation Oncol Biol Phys 2010; 77 (1): 73-78.

[62] Suit HD, Gallager HS. Intact tumor cells in irradiated tissue. Arch Pathol 1964; 78: 648-651. 